\title{
Novas Dinâmicas nas Relações Internacionais: o papel das cidades
}

New Dynamics in International Relations: the role of cities

Evelise Zampier da Silva ${ }^{1}$

\section{RESUMO}

O artigo analisa a crescente presença das cidades nas relações internacionais, em processos de troca de experiências, investimentos e tecnologia, através de cooperação mútua e busca de soluções comuns para problemas globais por elas vivenciados. A fim de instrumentalizar a abordagem teórica sobre o tema, traz diversos exemplos sobre o papel das cidades no cenário internacional.

Palavras-chave: cidades; cooperação.

\begin{abstract}
The article analyzes the increasing presence of cities in international relations in processes of exchange of experience, investments and technology, through mutual cooperation and seeking common solutions to global problems they experienced. In order to provide tools to the theoretical approach, it brings several examples about the role of cities in the international setting.
\end{abstract}

Keywords: cities; cooperation.

\section{Introdução}

O fim da Guerra Fria trouxe novas configurações ao cenário mundial, determinando uma redistribuição de forças e permitindo que o cenário, até então dominado pelos Estados-Nacionais, passasse a ser disputado por outros atores, entre os quais os entes subnacionais. Observou-se uma reordenação das estruturas domésticas que possibilitou a estes novos atores agir em prol dos interesses locais, o que, frequentemente, ocorre na lacuna de atuação do poder central.

Verifica-se uma intensa interação de unidades subnacionais, isoladamente ou em redes, em busca de soluções para problemas globais simultaneamente percebidos ou vivenciados como as questões ligadas à mobilidade, meio-ambiente, criminalidade, habitação, combate à pobreza. Nesse contexto, províncias, estados, regiões e

\footnotetext{
${ }^{1}$ Mestre em Gestão Urbana, linha de pesquisa Políticas Públicas, pela Pontifícia Universidade Católica do Paraná. Doutoranda do Programa de Pós-Graduação em Ciência Política da Universidade Federal do Paraná. Curitiba, Brasil. E-mail para contato: zampierdasilva@gmail.com

Conjuntura Global, Vol. 4, n. 1, jan./abr., 2015, p. 02-09. 
municipalidades passam a agir em esfera global, formando fortes conexões e profícuas parcerias voltadas aos mais diversos fins, da captação de investimentos à promoção do turismo, da cooperação técnica à busca de prestígio internacional.

0 presente artigo propõe uma reflexão sobre a inserção das cidades no cenário internacional e o papel que elas vêm desempenhando no desenvolvimento local através da sinergia com outros municípios. Aborda as motivações que fomentam a aproximação entre cidades e a formação de canais entre elas, elencando exemplos de conexões formadas a partir das mais diversas finalidades. Pretende suscitar, em desdobramentos subsequentes, um maior aprofundamento do tema em seus aspectos práticos, com ênfase nos resultados a nível local e nas interferências que a participação das cidades em assuntos de interesse global podem cooperar com a efetivação dos direitos individuais.

0 presente artigo se organiza em seções. Após esta introdução, discute-se a emergência das cidades no cenário internacional, elencando-se exemplos de como essa atuação vem ocorrendo. Conclui-se apontando sugestões para aprofundamento da análise da atuação das cidades na esfera internacional.

\section{A emergência das cidades no cenário internacional}

O incremento das relações supranacionais, ao mesmo tempo que fortaleceu instituições que estão acima do Estado, favoreceu o empoderamento de unidades subnacionais, como estados federativos, províncias, regiões e municipalidades, que passaram a ser atores internacionais de desenvolvimento. Gradualmente esses novos atores têm se destacado, assumindo papéis e se consolidando no cenário internacional.

0 processo, que amplia a esfera de assuntos internacionais, faz com que os Estados deixem de ser os únicos protagonistas (KEATING, 2000), e dá espaço para que outros entes, governamentais ou não, atuem em esfera global. Assim, entre as inúmeras consequências da globalização, surge uma nova abordagem sobre soberania, que resulta da inserção de novos atores (subnacionais, regionais, transnacionais) no cenário mundial, ainda que as funções de defesa, legitimidade para celebrar tratados, exercício da diplomacia oficial, direito à não intervenção, entre outros, subsistam como prerrogativas inerentes à noção de soberania clássica que detém o Estado. 
A análise dessa nova dinâmica deve considerar a coexistência de relações entre diferentes Estados, entre entes subnacionais de diferentes Estados, e também entre entes subnacionais diretamente com outro(s) Estado(s). Impõe também que se avalie a existência simultânea de temas de interesse global, nacional, regional e local, e como a emergência desses temas levarão à formação de redes para a solução de problemas comuns. Essas redes agiriam dentro do que Hurrel (1999) chamou de consciência moral cosmopolita - a busca por padrões mínimos de bem-estar e prosperidade para todo serhumano.

Atores estatais e não estatais vêm estabelecendo conexões a partir da percepção de problemas existentes em diferentes escalas e buscando, através de uma atuação convergente, ampliar sua atuação no âmbito mundial (CHASE-DUNN e LERRO, 2013). No cenário descrito, de múltiplo protagonismo, as cidades têm desempenhado papel relevante no intercâmbio de ideias e soluções, bem como na formação de redes de cooperação e na manutenção de uma arena de debate sobre temas de interesse comum que afetam municipalidades situadas em diferentes regiões do planeta.

Nesse contexto, a cooperação entre cidades favorece aquelas que se encontram em estágios mais incipientes de desenvolvimento, fazendo com que tecnologias e políticas públicas exitosas em localidades mais desenvolvidas possam ser replicadas em locais mais carentes de infraestrutura e investimentos. Permite um agir global em torno de problemas locais através da transferência das soluções, da discussão acerca das iniciativas já implementadas, dos resultados obtidos (positivos ou não) e do fortalecimento perante a comunidade internacional.

Harvey (1989, p. 266) defende que a diminuição de barreiras espaciais resulta na reafirmação e realinhamento hierárquicos no interior do que é hoje um sistema urbano global. Dentro desse sistema destacam-se as localidades que se posicionem de modo mais competitivo diante dos desafios atuais, o que implica, muitas vezes, num alinhamento vertical entre as cidades, de modo que aquelas que se situam em posição mais avançada - em termos de infraestrutura, tecnologia, economia, política - tornam-se exportadoras de ideias, conhecimentos, experiências e investimentos em prol das localidades com nível de desenvolvimento menor.

Sob a ótica de Harvey (1989), os padrões de conexão entre as cidades podem revelar quem é compelido por quem, quem é dependente do intercâmbio com outros, e a Conjuntura Global, Vol. 4, n. 1, jan./abr., 2015, p. 02-09. 
quem se pode dar crédito, o que, em última instância pode sinalizar quem exerce o poder dentro daquela estrutura (CONSIDINE et al. 2009)

Ao se tratar da integração horizontal das cidades em nível global, pode-se adotar a classificação de Pluijm e Melissen (2007), que elencam seis hipóteses mais comuns para a cooperação entre cidades: segurança, cultura, desenvolvimento, economia, network e representatividade. Cidades se aliam por motivos de segurança, visando à prevenção ou resolução de conflitos, bem como ações preventivas ou repressivas à criminalidade. Atuando nesse contexto, cita-se o European Forum for Urban Security (EFUS), que congrega trezentos membros de dezessete países, incluindo cidades, governos locais, instituições associadas e outros parceiros, e atua na troca de experiências, informações, tecnologia e conhecimento acerca da prevenção de crimes e de políticas de segurança urbana. Sob a classificação dos autores compreende-se também a aproximação de cidades guiadas por objetivos culturais, como ocorre com a União das Cidades Capitais Luso-África-Américo-Asiáticas (ou UCCLA-União das Cidades Capitais de Língua Portuguesa), que tem como uma das temáticas, o intercâmbio cultural entre as cidades-membro, e cuja origem decorre de um elemento cultural comum que é a língua portuguesa.

Outro exemplo são as redes de cidades que se formam em decorrência da proximidade geográfica, da participação em determinado bloco econômico ou do compartilhamento de problemas comuns. Temos como exemplo as Eurocities, rede formada pelas maiores cidades europeias, que atualmente reúne cento e trinta cidades, o Council of European Municipalities and Regions, que reúne representantes de cinquenta associações de cidades, municipalidades e regiões europeias, a rede Mercociudades, que engloba 272 cidades do Mercosul, com o objetivo de inseri-las no processo de integração regional do bloco, o Mega-Cities Project, formado por 18 das maiores regiões metropolitanas do mundo, com vistas à troca de ideias e inovações tecnológicas.

As relações cidade-cidade são um meio eficiente, mais rápido e menos burocrático de atrair investimentos, estabelecer parcerias, propiciar a circulação de bens e serviços, permitindo que as localidades consigam agir em nome próprio, desvinculando-se da imagem do Estado a que pertencem. Nesse contexto Neves (2010) salienta a atuação de Beijing, que, explorando canais mais informais, estabelece parcerias com países que não possuem relações com a China, o mesmo ocorrendo com 
as localidades chinesas de Guangdong (que tem como "províncias irmãs" Utrecht, na Holanda; Skane, na Suíça; e Côte d’Azur, na França); Jiangsu (que possui escritórios próprios de representação em Dusseldorf, na Alemanha; Paris, na França; Chelmsford, no Reino Unido e Estocolmo, na Suécia); e Shangai (com representações em Barcelona, Espanha; Milão, Itália; Roterdã, Holanda; Hamburgo, Alemanha; Liverpool, Inglaterra; Marselha, França e Antuérpia, Bélgica).

No Brasil, segundo Saraiva (2004), a democracia federativa ganha mais espaço a partir da Constituição de 1988, ainda que enfrente resistência do poder central que entende que o Estado é o único ator legítimo na esfera internacional. Assim, coexiste a high politics, executada diretamente pelo Estado², através da Presidência da República ou de organismos situados no governo federal, como a Agência Brasileira de Cooperação, com o predomínio de questões sensíveis (SARAIVA, 2004): matéria penal, criminalidade, defesa, questões sanitárias, emergências ambientais, etc., e a low politics, seara de atuação dos entes subnacionais.

Quanto à cooperação realizada pelos entes federativos, a falta de institucionalização faz com que a prática se situe no que Saraiva (2004) chamou de "limbo", que cria obstáculos à análise da atuação internacional dos municípios brasileiros, dificultando o debate acadêmico, a troca de experiências, a sistematização de informações, a divulgação de resultados, a captação de novas parcerias. A falta de organização de dados referentes à atuação internacional das cidades brasileiras remete às entidades que congregam municípios, como a Confederação Nacional dos Municípios (CMN). A instituição possui um vasto material a respeito das experiências empreendidas pelos municípios brasileiros, entre as quais, cita-se a cooperação técnica entre o município de São Bernardo do Campo/SP e o governo japonês com vistas à despoluição da represa Billings em São Paulo, o acordo entre Diadema/SP e a cidade de Montreaux (Suíça) para intercâmbio de alunos do ensino superior, a parceria entre Nova Friburgo/RJ e Alsace (França) para promoção do turismo rural, o convênio entre Guarulhos/SP e a cidade de Nanterre (França) em prol da formação da Rede FALP (Fórum de Autoridades Locais de Periferia) por Metrópoles Solidárias.

\footnotetext{
2 Exemplos de acordos celebrados entre o Brasil e demais países podem ser encontrados na base de dados do Senado Federal: http://legis.senado.leg.br/sicon/index.jsp?action=LegislacaoTextual. Acesso em $13 / 10 / 2014$. 
Vigevani (2006) afirma que o modelo brasileiro implementou "adaptações institucionais", que pretendem harmonizar o papel do Estado e a participação dos entes subnacionais na política exterior. Salienta que, embora teoricamente cogite-se a possibilidade de choque de interesses entre o Estado e as unidades regionais e locais, na prática quando estas atuam, o fazem em prol de temas que lhe são pertinentes e que dificilmente atentariam contra o poder central. Rodrigues (2008) destaca que ainda que sem previsão legal, estados e municípios brasileiros vêm atuando externamente em diversas áreas como saúde, meio ambiente, habitação, combate à pobreza, etc.

Importante ressaltar o posicionamento crítico de alguns pesquisadores brasileiros acerca das razões subliminares para emergência da diplomacia municipal em nosso país. Ainda que o resultado da atuação das cidades possa ser favorável, muitas vezes decorrem da delegação de poderes do Estado às municipalidades, pela incapacidade daquele de atender às demandas que seriam de sua competência, e também pelo descrédito e inércia do Estado, que leva as autoridades municipais a tomarem frente na resolução das questões locais, mesmo quando elas não seriam de sua competência (VIGEVANI e PRADO, 2010).

\section{Considerações finais}

A globalização tem como uma de suas consequências a emergência de uma arena de ação política que "facilita o fluxo de informações, a difusão de valores, conhecimentos e ideias, além de aumentar a capacidade de grupos afins (em opiniões e atitudes) de se organizar para além das fronteiras nacionais" (HURRELL:1999). É inegável a inserção das cidades nessa arena, como atores relevantes em temas ligados ao desenvolvimento e bem-estar social, cooperação em áreas de interesse local, estabelecimento de parcerias para solução de problemas comuns ou para a exportação de soluções já aplicadas internacionalmente.

As redes globais de cidades configuram um tema de especial interesse pois apresentam características muito peculiares. Entender a lógica com que ideias, experiências, conhecimentos e políticas públicas se propagam nessas redes de cidades pode explicar padrões de desenvolvimento, demonstrar porque determinadas inovações se difundem e outras não, bem como apontar razões de êxito ou de fracasso de 
determinadas decisões políticas. Essa análise traz respostas sobre a dinâmica das relações internacionais, suas polarizações, sobre cidades-líderes, sobre os impactos que a atuação conectada pode representar em termos locais e em termos globais.

Este artigo busca, de maneira introdutória, contribuir para a discussão sobre a participação das cidades na sociedade global. Desdobramentos futuros podem atentar para os fatores que levam as cidades a agir no cenário internacional ou as barreiras que impedem sua atuação fora dos limites nacionais, enfocando os elementos que compõem essa dinâmica, os mecanismos e atores intervenientes e os temas que preponderam no debate. Dissecar os componentes do processo de inserção internacional das cidades pode, igualmente, contribuir com o aperfeiçoamento de tais relações, principalmente considerando-se uma perspectiva cosmopolita, que entenda a intensificação da presença do componente local no cenário global como uma possibilidade de efetivação de valores centrados na melhoria da qualidade de vida dos indivíduos. 


\section{REFERÊNCIAS}

CONSIDINE, Mark; LEWIS, Jenny; ALEXANDER, Damon. Networks, innovation and public policy - politicians, bureaucrats and the pathways to change inside government. $1^{\mathrm{a}}$ ed. Hampshire: Palgrave-Macmillan, 2009.

HARVEY, David. Condição Pós-Moderna, uma pesquisa sobre as origens da mudança cultural. 10ª ed. São Paulo: Edições Loyola, 2001.

HURREL, Andrew. Sociedade Internacional e Governança Global. Lua Nova, São Paulo, n. 46, p. 55-75, 1999.

KEATING, Michael. Paradiplomacy and Regional Networking. Forum of Federations: an International Federalism - Hanover, October 2000. Disponível em: http://www.forumfed.org/libdocs/ForRelCU01/924-FRCU0105-eu-keating.pdf. Acesso em 20/07/2013

PLUIJM, Rogier; MELISSEN, Jan. City Diplomacy: The expanding role of cities in international politics. Netherlands Institute of International Relations Clingendael. The Hague, Clingendael Diplomacy Papers, n. 10, april, 2007.

NEVES, Miguel Santos. Paradiplomacy, knowledge regions and the consolidation of «Soft Power». Disponível em: observare.ual.pt/janus.net/en_vol1_n1_art2, acesso em 20 de julho de 2013.

RODRIGUES, Gilberto Marcos Antonio. Relações Internacionais Federativas no Brasil. Revista de Ciências Sociais, Rio de Janeiro, v. 51, n. 4, p. 1015-1034, 2008.

SARAIVA, José Flávio Sombra. Do federalismo centralista ao paradigma do federalismo cooperativo: as relações internacionais do Brasil e sua política de comércio exterior. Integración \& Comércio, Buenos Aires, n. 21, jul/dez, 2004.

VIGEVANI, Tullo. Problemas para a atividade internacional das unidades subnacionais: estados e municípios brasileiros. Revista Brasileira de Ciências Sociais, São Paulo, v. 21, n. 62, p. 127-139, 2006.

VIGEVANI, Tullo; PRADO, Débora Figueiredo. Ações e Problemas para a Paradiplomacia no Brasil. In: SALA, José; GASPAROTO, Ana Lúcia (Orgs.) Relações internacionais: polaridades e novos/velhos temas emergentes. Marília: Unesp, Oficina Universitária, 2010.

CONFEDERAÇÃO NACIONAL DOS MUNICÍPIOS (CNM) Cooperação Descentralizada Franco-Brasil. Brasília: CNM, 2009. 